\title{
PCR-Based Restriction Fragment Length Polymorphism (RFLP) Analysis of Campylobacter jejuni Isolates from Humans, Chickens and Dogs in Northern Taiwan
}

\author{
Hsiang-Jung TSAI ${ }^{1) *}$, Huang-Chi HUANG ${ }^{1)}$, Huei-Lin $\mathrm{TSAI}^{2)}$ and Cha-Chin $\mathrm{CHANG}^{2)}$ \\ ${ }^{1)}$ Department of Veterinary Medicine, National Taiwan University, Taipei 106, Taiwan and ${ }^{2)}$ Mackay Memorial Hospital, Taipei 104, \\ Taiwan
}

(Received 9 November 2005/Accepted 28 March 2006)

\begin{abstract}
Two hundred and twenty strains of Campylobacter jejuni (70 human, 51 canine and 99 chicken strains) were isolated from September 2003 to September 2004 in northern Taiwan. These strains were subtyped by PCR-RFLP analysis of the flagellin (FlaA) gene. On the basis of restrictive digest, six types were identified with $A f a I$, seven types with $M b o$ I and five types with HaeIII. With the combination of these three enzymes, 47 distinct PCR-RFLP patterns were observed-25 each from human and chicken isolates, and 9 from canine isolates. In human strains, the most frequently occurring types were $\mathrm{Cj}-28(14.3 \%), \mathrm{Cj}-17(10 \%), \mathrm{Cj}-16(8.6 \%), \mathrm{Cj}-37(7.1 \%)$ and $\mathrm{Cj}-46$ (7.1\%). In canine strains, the most prevalent types were $\mathrm{Cj}-1$ (33.3\%), $\mathrm{Cj}-26(19.6 \%), \mathrm{Cj}-3$ (15.7\%), $\mathrm{Cj}-2$ (9.8\%) and $\mathrm{Cj}-10$ (9.8\%). In chicken strains, the most frequently occurring types were $\mathrm{Cj}-46(40.4 \%), \mathrm{Cj}-29(9.1 \%), \mathrm{Cj}-45(7.1 \%)$ and $\mathrm{Cj}-41(5.1 \%)$. The results suggest that poultry is a source, but not the sole source, of $C$. jejuni infection in humans. Two RFLP types, $\mathrm{Cj}-17$ and $\mathrm{Cj}-37$, frequently occurring in human isolates in this study have also been found to be prevalent in human isolates in Japan, China and the Czech Republic, indicating a possible international clonal spread.
\end{abstract}

KEY WORDS: Campylobacter jejuni, canine, chicken, human, PCR-RFLP analysis.

J. Vet. Med. Sci. 68(8): 815-819, 2006

Campylobacter jejuni and, to a lesser extent, C. coli are major causes of gastroenteritis in humans $[12,23]$. Localized Campylobacter infections of a variety of organs have also been rarely linked with Guillain-Barré syndrome (GBS), reactive arthritis, Reiter's syndrome, hemolytic uremic syndrome (HUS), and septicemia $[1,2]$. Recently, immunodeficiency states (for example, immunosuppressive drugs, acquired immunodeficiency syndrome and the expanding elderly group) have made $C$. jejuni infections even more significant in the human population [25]. The majority of cases of human campylobacteriosis in developed countries are most probably caused by consumption of undercooked poultry, raw milk, or untreated surface water $[4,15]$. It has been reported that the main source of Campylobacter spp. infection is the consumption of contaminated poultry products $[7,24]$. The organism is present in a high percentage of clinically normal farmed poultry $[5,6]$. Living in a household with a dog has also been identified as a significant risk factor for acquiring this disease [15, 25]. Most infected dogs act as asymptomatic reservoirs, shedding Campylobacter in their stools and ultimately infecting other animals by contaminating the environment [11].

Because of the multiple sources of infection in humans, there is a need for epidemiological typing methods to determine the source of infection and route of transmission. During the past decade, traditional typing methods, such as bacteriophage typing and serotyping, have been replaced by newer techniques, such as plasmid fingerprinting, ribotyping, polymerase chain reaction (PCR)-based methods and pulsed-field gel electrophoresis (PFGE) [32]. Pulsed-field gel electrophoresis (PFGE) is a highly discriminatory and reproducible method for the typing of $C$. jejuni $[14,28,29]$. Unfortunately it is labor intensive and time consuming. An alternative method that is simple, fast, cheap and has sufficient discriminatory power is PCR-restriction fragment length polymorphism (RFLP) of the highly variable flagellin gene (flaA) [3, 10, 21, 26, 34]

C. jejuni, and to a lesser extent $C$. coli and C. lari, is an important cause of infectious enteritis in Taiwan [18]. The isolation rate of Campylobacter species ranged from $1.9 \%$ to $5.6 \%$ in the patients with diarrhea or gastroenteritis in Taiwan [9, 18, 31]. It has been shown that campylobacter enteritis occurs throughout the year in Taiwan, but predominantly occurred in the winter $[18,33]$ and majority of the campylobacter enteritis patients were younger than 5 years $[18,33]$. It has also been shown that $C$. jejuni isolates from humans were significantly more susceptible than chicken strains to erythromycin, clindamycin and ciprofloxacin [17], but to the best of the author's knowledge, no molecular comparisons of the $C$. jejuni human isolates and animal isolates have been conducted in Taiwan. The objectives of this study were to evaluate the genomic diversity by PCR-RFLP of $C$. jejuni strains from humans, chickens and dogs in northern Taiwan and to determine possible epidemiologic relationships.

\section{MATERIALS AND METHODS}

Bacterial strains: Seventy strains of Campylobacter jejuni were isolated from fecal specimens of patients treated for enteritis in Mackay Memorial Hospital (Taipei City) during the period from September 2003 to June 2005. Fiftyone strains of $C$. jejuni were isolated from rectal swab cultures collected from impounded dogs in six public animal shelters located in northern Taiwan. Each shelter was visited twice at least three months apart and all the dogs in the 
shelters were sampled on each occasion. Another 99 strains of $C$. jejuni were isolated from a poultry processing plant that received broilers, mainly from northern Taiwan. The processing plant was visited twice at least three months apart and 20 chickens from each farm were sampled on each occasion.

Culture and identification: The bacteria were cultured on cefoperazone vancomycin amphotericin B (Campy CVA) agar plates (BBL, Becton, Dickinson and Company, Franklin Lakes, NJ) and incubated at $42^{\circ} \mathrm{C}$ under microaerophilic conditions $\left(10 \% \mathrm{CO}_{2}, 5 \% \mathrm{O}_{2}\right.$, and $\left.85 \% \mathrm{~N}_{2}\right)$. Preliminary identification of Campylobacter was based on phenotypic characteristics: colonial appearance, microscopic morphology, motility, oxidase and catalase reactions. The polymerase chain reaction (PCR)-based restriction fragment length polymorphism (RFLP) analysis for the flagellin $A$ (flaA) gene previously described by Nishimura et al. [22] was used to further confirm and subtype $C$. jejuni.

PCR-RFLP analysis: The genomic DNA of Campylobacter colonies was extracted using a commercial SpinClean $^{\mathrm{TM}}$ Genomic DNA Purification Kit (MBI Fermentas GMBH, St. Leon-Rot, Germany). For each PCR, $5 \mu l$ of the prepared DNA sample was added to $50 \mu \mathrm{l}$ reaction mix containing $1.5 \mathrm{mM} \mathrm{MgCl}_{2}, 200 \mu \mathrm{M}$ each deoxynucleotide, 0.2 $\mu \mathrm{M}$ each primer, 1 Unit Taq polymerase (BerTaq polymerase, Bertec Corporation, Columbus, $\mathrm{OH}$ ) and $5 \mu l 10 \mathrm{X}$ buffer (Viogene, Sunnyvale, CA). The two commercially synthesized primers were a 20 bp forward primer 5'-TACTACAGGAGTTCAAGCTT-3' and a 20 bp reversed primer 5'-GTTGATGTAACTTGATTTTG-3'. Both primers have been described previously [22] and gave the predicted product of $702 \mathrm{bp}$ representing the variable (V1) region. The PCR cycle used consisted of an initial denaturation at $94^{\circ} \mathrm{C}$ for $2 \mathrm{~min}$; 35 cycles of denaturation at $94^{\circ} \mathrm{C}$ for $30 \mathrm{sec}$, primer annealing at $51^{\circ} \mathrm{C}$ for $35 \mathrm{sec}$, and an extension step at $72^{\circ} \mathrm{C}$ for $1 \mathrm{~min}$; and final extension at $72^{\circ} \mathrm{C}$ for $10 \mathrm{~min}$. PCR was performed using a GeneAmp PCR system 9700 thermal cycler (Applied Biosystems, Foster City, CA). PCR products $(10 \mu l)$ were added in $10 \mu l$ reaction buffer
(Takara, Takara Shuzo Co., Ltd., Shiga, Japan) with 3 U of restriction enzymes $A f a \mathrm{I}, M b o \mathrm{I}$ and HaeIII (Takara, Japan). The reaction mixture was incubated at $37^{\circ} \mathrm{C}$ for $5 \mathrm{hr}$. The products of the digest were analyzed on $3 \%$ agarose gel (Promega, Madison, WI). One hundred bp DNA Ladder (Promega) was used as a standard size marker.

\section{RESULTS}

The comparison of RFLP patterns of 70 C. jejuni isolates from humans, 51 from dogs and 99 from chickens revealed an expected high heterogeneity among strains. Based on restriction digest, six types of RFLP patterns were detect with $A f a \mathrm{I}$, seven with $M b o \mathrm{I}$ and five with HaeIII (Fig. 1). Combination of these enzymes revealed 47 types $(\mathrm{Cj}-1$ to $\mathrm{Cj}-47$ ), of which 25 occurred in human isolates, 11 in canine isolates and 25 in poultry isolates. The number of strains exhibiting each flaA RFLP pattern is listed in Table 1.

The most frequently detected type in human strains was $\mathrm{Cj}-28$ (14.3\%), followed by $\mathrm{Cj}-17$ (10\%), Cj-16 (8.6\%), Cj$37(7.1 \%)$ and $\mathrm{Cj}-46(7.1 \%)$. Further types were detected only in one to four strains. In C. jejuni canine strains, nine patterns were found, the most prevalent being $\mathrm{Cj}-1$ (33.3\%), followed by $\mathrm{Cj}-26$ (19.6\%), $\mathrm{Cj}-3$ (15.7\%), $\mathrm{Cj}-2$ (9.8\%) and $\mathrm{Cj}-10(9.8 \%)$. Further types were detected only in one strain. In $C$. jejuni poultry strains, 25 patterns were found, the most frequently occurring being $\mathrm{Cj}-46$ (40.4\%), followed by Cj-29 (9.1\%), Cj-45 (7.1\%) and $\mathrm{Cj}-41(5.1 \%)$. Further types were detected only in one to four strains.

From these results, it is evident that the majority of the prevalent types (occurring in $>5 \%$ of isolates) were different among human, canine and poultry strains. The only overlapping types were $\mathrm{Cj}-41$, which accounted for $5.7 \%$ of the human strains and $5.1 \%$ of the poultry strains, and $\mathrm{Cj}-46$, which constituted $7.1 \%$ of the human strains and $40.4 \%$ of the poultry strains. Of the 25 types of $C$. jejuni detected in humans, only six types occurred, with various frequencies, in both human and dog, and only seven types occurred, with various frequencies, in both human and poultry. Thirteen (a)
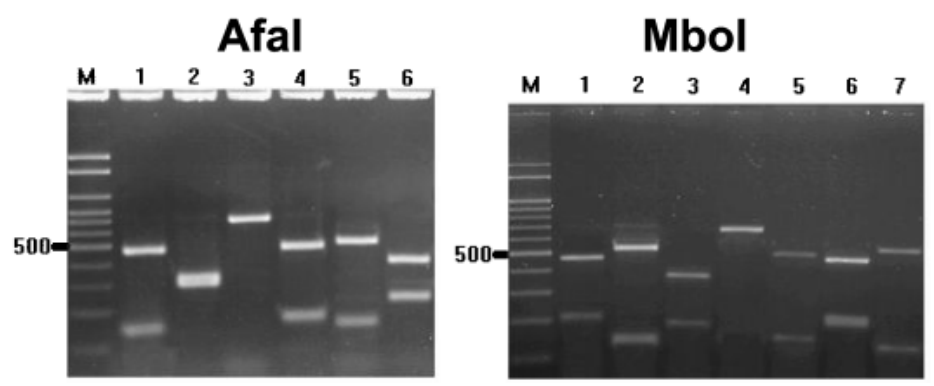

(b)

(c)

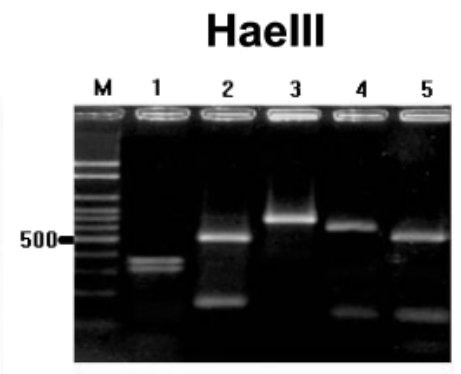

Fig. 1. Representative restriction endonuclease digests of the PCR-amplified, 702 bp flagellin A region of Campylobacter jejuni. RFLP patterns obtained by $A f a \mathrm{I}$, six patterns (a), MboI, seven patterns (b) and HaeIII, five patterns (c) are shown. (a) Lane M: 100 bp DNA Ladder; lane 1-6: AfaI 6 patterns, 1-6, respectively. (b) Lane M: 100 bp DNA Ladder; lane 1-7: MboI 7 patterns, 1-7, respectively. (c) Lane M: 100 bp DNA Ladder; lane 1-5: HaeIII 5 patterns, $1-5$, respectively. 
Table 1. RFLP typing scheme profiles of Campylobacter jejuni isolates from human, dog and chicken

\begin{tabular}{|c|c|c|c|c|c|}
\hline \multirow{2}{*}{\multicolumn{2}{|c|}{$\begin{array}{l}\text { Restriction RFLP type } \\
\text { pattern number } \\
(\text { AfaI-MboI-HaeIII) }\end{array}$}} & \multicolumn{3}{|c|}{ Source of strains } & \multirow{2}{*}{$\begin{array}{l}\text { Total } \\
(\mathrm{n}=220)\end{array}$} \\
\hline & & \multirow{2}{*}{$\begin{array}{l}\begin{array}{l}\text { Human } \\
(\mathrm{n}=70)\end{array} \\
0\end{array}$} & \multirow{2}{*}{$\begin{array}{l}\begin{array}{l}\text { Dog } \\
(n=51)\end{array} \\
17(33.3 \%)\end{array}$} & \multirow{2}{*}{$\begin{array}{l}\text { Chicken } \\
(\mathrm{n}=99)\end{array}$} & \\
\hline$(1-1-1)$ & $\mathrm{Cj}-1$ & & & & $17(7.7 \%)$ \\
\hline$(1-4-1)$ & $\mathrm{Cj}-2$ & 0 & $5(9.8 \%)$ & 0 & 5 \\
\hline$(1-6-1)$ & $\mathrm{Cj}-3$ & 1 & $8(15.7 \%)$ & 0 & 9 \\
\hline$(1-6-5)$ & $\mathrm{Cj}-4$ & 0 & 1 & 0 & 1 \\
\hline$(2-4-3)$ & $\mathrm{Cj}-5$ & $4(5.7 \%)$ & 0 & 0 & 4 \\
\hline$(2-5-3)$ & $\mathrm{Cj}-6$ & 1 & 0 & 0 & 1 \\
\hline$(2-7-3)$ & $\mathrm{Cj}-7$ & 3 & 1 & 0 & 4 \\
\hline$(3-1-2)$ & $\mathrm{Cj}-8$ & 0 & 0 & 1 & 1 \\
\hline$(3-2-2)$ & $\mathrm{Cj}-9$ & 0 & 1 & 0 & 1 \\
\hline$(3-2-3)$ & $\mathrm{Cj}-10$ & 0 & $5(9.8 \%)$ & 0 & 5 \\
\hline$(3-3-2)$ & $\mathrm{Cj}-11$ & 0 & 0 & 2 & 2 \\
\hline$(3-3-3)$ & $\mathrm{Cj}-12$ & 0 & 0 & 2 & 2 \\
\hline$(3-3-4)$ & $\mathrm{Cj}-13$ & 0 & 0 & 4 & 4 \\
\hline$(3-3-5)$ & $\mathrm{Cj}-14$ & 0 & 0 & 4 & 4 \\
\hline$(3-4-2)$ & $\mathrm{Cj}-15$ & $4(5.7 \%)$ & 0 & 4 & 8 \\
\hline$(3-4-3)$ & $\mathrm{Cj}-16$ & $6(8.6 \%)$ & 0 & 0 & 6 \\
\hline$(3-4-4)$ & $\mathrm{Cj}-17$ & $7(10 \%)$ & 1 & 2 & 10 \\
\hline$(3-4-5)$ & $\mathrm{Cj}-18$ & 2 & 0 & 1 & 3 \\
\hline$(3-5-3)$ & $\mathrm{Cj}-19$ & 0 & 0 & 1 & 1 \\
\hline$(3-5-4)$ & $\mathrm{Cj}-20$ & 1 & 0 & 0 & 1 \\
\hline$(3-6-2)$ & $\mathrm{Cj}-21$ & 2 & 0 & 0 & 2 \\
\hline$(3-6-3)$ & $\mathrm{Cj}-22$ & $4(5.7 \%)$ & 1 & 0 & 5 \\
\hline$(3-6-4$ & $\mathrm{Cj}-23$ & 1 & 0 & 0 & 1 \\
\hline$(3-6-5)$ & $\mathrm{Cj}-24$ & 1 & 0 & 0 & 1 \\
\hline$(3-7-2)$ & $\mathrm{Cj}-25$ & 1 & 0 & 0 & 1 \\
\hline$(3-7-3)$ & $\mathrm{Cj}-26$ & 1 & $10(19.6 \%)$ & 0 & $11(5 \%)$ \\
\hline$(3-7-4)$ & $\mathrm{Cj}-27$ & 1 & 0 & 1 & 2 \\
\hline$(4-4-3)$ & $\mathrm{Cj}-28$ & $10(14.3 \%)$ & 1 & 3 & $14(6.4 \%)$ \\
\hline$(4-5-3)$ & $\mathrm{Cj}-29$ & 0 & 0 & $9(9.1 \%)$ & 9 \\
\hline$(4-6-3)$ & $\mathrm{Cj}-30$ & 0 & 0 & 3 & 3 \\
\hline$(4-6-4)$ & $\mathrm{Cj}-31$ & 0 & 0 & 2 & 2 \\
\hline$(5-2-3)$ & $\mathrm{Cj}-32$ & 1 & 0 & 0 & 1 \\
\hline$(5-3-2)$ & $\mathrm{Cj}-33$ & 0 & 0 & 1 & 1 \\
\hline$(5-3-3)$ & $\mathrm{Cj}-34$ & 0 & 0 & 1 & 1 \\
\hline$(5-3-4)$ & $\mathrm{Cj}-35$ & 0 & 0 & 1 & 1 \\
\hline$(5-4-2)$ & $\mathrm{Cj}-36$ & 0 & 0 & 1 & 1 \\
\hline$(5-4-3)$ & $\mathrm{Cj}-37$ & $5(7.1 \%)$ & 0 & 0 & 5 \\
\hline$(5-4-4)$ & $\mathrm{Cj}-38$ & 1 & 0 & 1 & 2 \\
\hline$(5-6-3)$ & $\mathrm{Cj}-39$ & 1 & 0 & 0 & 1 \\
\hline$(5-7-2)$ & $\mathrm{Cj}-40$ & 1 & 0 & 0 & 1 \\
\hline$(5-7-3)$ & $\mathrm{Cj}-41$ & $4(5.7 \%)$ & 0 & $5(5.1 \%)$ & 9 \\
\hline$(5-7-4)$ & $\mathrm{Cj}-42$ & 0 & 0 & 1 & 1 \\
\hline$(5-7-5)$ & $\mathrm{Cj}-43$ & 0 & 0 & 1 & 1 \\
\hline$(6-4-2)$ & $\mathrm{Cj}-44$ & 2 & 0 & 0 & 2 \\
\hline$(6-4-3)$ & $\mathrm{Cj}-45$ & 0 & 0 & $7(7.1 \%)$ & 7 \\
\hline$(6-4-4)$ & $\mathrm{Cj}-46$ & $5(7.1 \%)$ & 0 & 40 (40.4\%) & $45(20.5 \%)$ \\
\hline$(6-5-4)$ & $\mathrm{Cj}-47$ & 0 & 0 & 1 & 1 \\
\hline
\end{tabular}

types were solely detected in human strains, five solely in canine strains, and 17 only in poultry strains.

\section{DISCUSSION}

Various restriction endonucleases have been chosen for the RFLP analysis of the flaA genes, such as DdeI [21], HinfI [26] and EcoRI/PstI [3]. Nishimura et al. [22] intro- duced the used of three restriction endonucleases, AfaI, MboI and HaeIII. With the combination of these three enzymes, 25 C. jejuni types were found in human strains from China and Japan [22]. Later, 22 types were found in the Czech Republic, including 20 types in human strains and nine types in chicken strains [27]. In this study, we found many more types - a total of 47 types, with 25 in human strains, 11 in strains from stray dogs, and 25 in strains from 
chickens. The finding of extensive genetic diversity in $C$. jejuni isolates is in accordance with previous reports.

Global spread of a major clone of HS-19 serotype $C$. jejuni has been documented [20]. Similarly, two RELP types ( $\mathrm{Cj}-17$ and $\mathrm{Cj}-37)$ identified in this study might also spread internationally, since $\mathrm{Cj}-17$ RFLP type (restriction pattern 3-4-4) accounts for $31.9 \%$ of Japanese human isolates [22], 28\% of those in the Czech Republic [27], 11.8\% of those in China [22] and $10 \%$ of Taiwanese human isolates, while $\mathrm{Cj}-37$ (restriction pattern 5-4-3) was found in $19 \%$ of Czech [27], $17.4 \%$ of Japanese [22], 10.6\% of Chinese [22] and $7.1 \%$ of Taiwanese human isolates, respectively.

Although Cj-17 RFLP type (restriction pattern 3-4-4) was common in human isolates from four countries, it only accounts for $2.0 \%$ and $1.8 \%$ of Taiwanese and Czech poultry isolates [27] and $2.0 \%$ of Taiwanese canine isolates. The Cj-37 molecular type (restriction pattern 5-4-3) was the most prevalent type in Czech poultry isolates (34\%) [27] but not found in Taiwanese poultry and canine isolates. In Taiwan the most prevalent molecular type of poultry isolates, Cj-46 (pattern 6-4-4), accounted for 7.1\% of the human isolates and was not found in canine isolates. The results indicate that poultry might be a source of human infection, but that sources other than poultry exist and that human $C$. jejuni infections are from multiple sources.

It is alarming that the most prevalent RFLP type of $C$. jejuni in stray dogs was $\mathrm{Cj}-1$ (pattern 1-1-1); because it was shown by Nishimura et al. [22] that this molecular type is significantly associated with the HS-19 serotype. Most of C. jejuni isolates from Guillain-Barré syndrome (GBS) patients belong to the HS-19 serotype $[13,16,30,35]$. In our study, we did not find the $\mathrm{Cj}-1$ (pattern 1-1-1) type in human isolates. This may be because the bacteria were isolated from enteritis, not GBS, patients. This molecular type was also not found in human strains from Czech patients suffering from enteritis; nor, as in the present study, was it found in poultry strains [27]. On the other hand, the $\mathrm{Cj}-1$ (pattern 1-1-1) type accounts for 5.8\% and $10.6 \%$ of the human $C$. jejuni isolates from diarrheic patients in Japan and China, respectively [22]. In a study in northern China, $C$. jejuni infection was a risk factor for GBS [19], but an association between previous $C$. jejuni infection and GBS was not found in a study in southern Taiwan [8]. Thus the significance of the predominant $\mathrm{Cj}-1$ RFLP type in stray dogs as a public health hazard for residents in Taiwan may need further study.

ACKNOWLEDGEMENT. This work was supported by a grant from the Council of Agriculture [92AS-1.8.2-BQ-B3 and 93AS-1.9.1-BQ-B3], Taiwan.

\section{REFERENCES}

1. Allos, B.M. 1997. Association between Campylobacter infection and Guillain-Barré Syndrome. J. Infect. Dis. 176: S125128.

2. Allos, B.M. 1998. Campylobacter jejuni infections as a cause of Guillain-Barré Syndrome. Infect. Dis. Clin. North Am. 12: 173.

3. Alm, R.A., Guerry, P. and Trust, J.J. 1993. Distribution and polymorphism of the falgellin genes from isolates of Campylobacter coli and Campylobacter jejuni. J. Bacteriol. 175: 30513057.

4. Altekruse, S.F., Hunt, J.M., Tollefson, L.K. and Madden, J.M. 1994. Food and animal sources of human Campylobacter jejuni infection. J. Am. Vet. Med. Assoc. 204: 57-61.

5. Atanassova, V. and Ring, C. 1999. Prevalence of Campylobacter spp. in poultry and poultry meat in Germany. Int. J. Food Microbiol. 51: 187-190.

6. Berndtson, E., Emanuelson, U., Engvall, A. and DanielssonTham, M. -L. 1996. A 1-year epidemiological study of campylobacters in 18 Swedish chicken farms. Prev. Vet. Med. 26: 167-185.

7. Bryan, F. and Doyle, M. 1995. Health risks and consequences of Salmonella and Campylobacter jejuni in raw poultry. $J$. Food Prot. 58: 326-344.

8. Cheng, B.C., Chang, W.N., Chang, C.S., Chee, C.Y., Huang, C.R., Chen, J.B., Chang, C.J., Hung, P.L., Wang, K.W. and Lu, C.H. 2003. Guillain-Barre syndrome in southern Taiwan: clinical features, prognostic factors and therapeutic outcomes. Eur. J. Neurol. 10: 655-662.

9. Chyou, S.C., Leu, Y.J., Huang, F.Y., Lee, H.C. and Yang, D.I. 1988. An etiological study of infectious diarrhea in infants and children in Taipei area. Acta Paed Sin 29: 213-220.

10. Fitzgerald, C., Stanley, J., Andrew, S. and Jones, K. 2001. Use of pulsed-field gel electrophoretsis and flagellin gene typing in identifying clonal groups of Campylobacter jejuni and Campylobacter coli in farm and clinical environments. Appl. Environ. Microbiol. 67: 1429-1436.

11. Fox, J.G. 1990. Campylobacteriosis. pp. 538-542. In: Infectious Disease of the Dog and Cat ed. Greene, C.E. Philadelphia, PA: WB Saunders.

12. Friedman, C., Neimann, J., Wegener, H. and Tauxe, R. 2000. Epidemilogy of Campylobacter jejuni infections in the United States and other industrialized nations, pp. 121-138. In: Campylobacter, 2 ed. (Nachamkin, I. and Blaser, M. eds.), ASM Press, Washington, DC.

13. Fujimoto, S., Yuki, N., Itoh, T. and Amako, K. 1992. Specific serotype of Campylobacter jejuni associated with GuillainBarré syndrome. J. Infect. Dis. 165: 183.

14. Hanninen, M.-L., Perko-Makela, P., Rautelin, H., Duim, B. and Wagenaar, J.A. 2001. Genomic relatedness within 5 common Finnish Campylobacer jejuni pulse-field gel electrophoresis genotypes studied by amplified fragment length polymorphism analysis, ribotyping and serotyping. Appl. Environ. Microbiol. 67: 1581-1586.

15. Kapperud, G., Skjerve, E., Bean, N.H., Ostroff, S.M. and Lassen, J. 1992. Risk factors for sporadic Campylobacter infections: results of a case-control study in southeastern Norway. $J$. Clin. Microbiol. 30: 3117-3121.

16. Kuroki, S., Saida, T., Nukina, M., Haruta, T., Yoshioka, M., Kobayashi, Y. and Nakanishi, H. 1993. Campylobacter jejuni strains from patients with Guillain-Barré syndrome beling mostly to Penner serogroup 19 and contain $\beta$-N-acetylglucosamine residue. Ann. Neurol. 33: 243-247.

17. Li, C.C., Chiu, C.H., Wu, J.L., Huang, Y.C. and Lin, T.Y. 1998. Antimicrobial susceptibilities of Campylobacter jejuni and coli by using E-test in Taiwan. Scand. J. Infect. Dis. 30: $39-42$.

18. Lin, C.W., Yin, P.L. and Cheng, K.S. 1998. Incidence and clin- 
ical manifestations of Campylobacter enteritis in central Taiwan. Zhonghua Yi Xue Zhi (Taipei) 61: 339-345.

19. McKhann, G.M., Cornblath, D.R., Griffin, J.W., Ho, T.W., Li., C.Y., Jiang, Z., Wu, S.W., Zhaori, G., Liu, Y., Jou, L.P, Liu, T.C., Gao, C.Y., Mao, J.Y., Blaser, M.J., Mishu, B. and Asbury, A.K. 1993. Acute motor axonal neuropathy: a frequent cause of acute flaccid paralysis in China. Ann. Neurol. 33: 333-342.

20. Nachamkin, I., Engberg, J., Gutacker, M., Meinersman, R.J., Li, C.Y., Arzate, P., Teeple, E., Fussing, V., Ho, T.W., Asbury, A.K., Griffin, J.W., McKhann, G.M. and Piffaretti, J.-C. 2001. Molecular population genetic analysis of Campylobacter jejuni HS: 19 associated GBS and gastroenteritis. J. Infect. Dis. 184: 221-226.

21. Nachamkin, I., Ung, H. and Patton, C.M. 1996. Analysis of HL and $\mathrm{O}$ serotypes of Campylobacter strains by flagellin gene typing system. J. Clin. Microbiol. 34: 277-281.

22. Nishimura, M., Nukina, M., Yuan, J.M., Shen, B.Q., Ma, J.J., Ohta, M., Saida, T. and Uchiyama, T. 1996. PCR-based restriction fragment length polymorphism (RFLP) analysis and serotyping of Campylobacter jejuni isolates from diarrheic patients in China and Japan. FEMS Microbiol. Lett. 142: 133-138.

23. Padungton, P. and Kaneene, J. B. 2003. Campylobacter spp. in human, chickens, pigs and their antimicrobial resistance. $J$. Vet. Med. Sci. 65: 161-170.

24. Park, C. E., Stankiewicz, Z. K., Lovett, J. and Hunt, J. 1981. Incidence of Campylobacter jejuni in fresh eviscerated whole market chickens. Can. J. Microbiol. 27: 841-842.

25. Robinson, R.A. and Pugh, R.N. 2002. Dogs, zoonoses and immunosuppression. J. Royal Soc. Health. 122: 95-98.

26. Santesteban, E., Gibson, J. and Owen, R.J. 1996. Flagellin gene profiling of Campylobacter jejuni heat-stable serotype 1 and 4 complex. Res. Microbiol. 147: 641-649.
27. Steinhauserova, I., Ceskova, J. and Nebola, M. 2002. PCR/ restriction fragment length polymorphims (RFLP) typing of human and poultry Campylobacter jejuni strains. Lett. Appl. Microbiol. 34: 354-358.

28. Suzuki, Y., Ishihara, M., Funabashi, M., Suzuki, R., Isomura, S. and Yokochi, T. 1993. Pulsed-filed gel electrophoretic analysis of Campylobacter jejuni DNA for use in epidemiological studies. J. Infect. 27: 39-42.

29. Suzuki, Y., Ishihara, M., Saito, M., Ishikawa, N. and Yokochi, T. 1994. Discriminaion by means of pulsed-filed gel electrophoresis between strains of Campylobacter jejuni Lior type 4 derived from sporadic cases and from outbreaks of infection. $J$. Infect. 29: 183-187.

30. Takahashi, M., Koga M., Yokoyama, K. and Yuki, N. 2005. Epidemiology of Campylobacter jejuni isolated from patients with Guillain- Barré and Fisher syndrome in Japan. J. Clin. Microbiol. 43: 335-339.

31. Tang, R.B., Hsieh, K.S. and Hwang, B. 1984. Campylobcter jejuni enteritis in children. Chin. J. Microbiol. Immunol. 17: 226-232.

32. Tenover, F.C., Arbeit, R.D., Goering, R.V., Mickelsen, P.A., Murray, B.E., Persing, D.H. and Swaminathan, B. 1995. Interpreting chromosomal DNA restriction pattern produced by pulse-field gel electrophoresis: criteria for bacterial strain tryping. J. Clin. Microbiol. 33: 2233-2239.

33. Tsai, W.Y., Hsu, J.Y. and Ho, S.W. 1985. Campylobacter enteritis in children. Acta Paed. Sin. 26: 436-442.

34. Wassenar, T.M. and Newell, D.G. 2000. Genotyping of Campylobacter spp. Appl. Environ. Microbiol. 66: 1-9.

35. Yuki, N., Takahashi, M., Tagawa, Y., Kashiwase, K., Tadoloro, K. and Saito, K. 1997. Associatin of Campylobacter jejuni serotype with antiganglioside antibody in Guillain- Barré syndrome and Fisher's syndrome. Ann. Neurol. 42: 28-33. 